\section{Transcriptional profile of bovine preimplantation development selected based on G6PDH activity}

\author{
Nasser Ghanem ${ }^{1 *}$, Romysa Samy1, Eman Kh Kassab1, \\ Beshoy SF Khalil ${ }^{1}$, Aya Ahmed Kordy ${ }^{1}$, Marwa MH Said ${ }^{1}$, \\ Nouran S Rashed ${ }^{1}$, Md Fakruzzamana ${ }^{2}$ and Kong IK ${ }^{3}$
}

\author{
${ }^{1}$ Animal Production Department, Faculty of Agriculture, Cairo University Research Park, Cairo \\ University, Egypt \\ ${ }^{2}$ Department of Genetics and Animal Breeding, Faculty of Animal Science and Veterinary \\ Medicine, Patuakhali Science and Technology University, Out Campus, Khanpura, Babuganj, \\ Barishal-8210, Bangladesh \\ ${ }^{3}$ Division of Applied Life Science (BK21), Graduate School of Gyeongsang National University, \\ Jinju 660-701, Republic of Korea
}

\section{Abstract}

The oocyte is the female gamete that contributes not only half of the genetic material but also all of the cytoplasm to the zygote, supplying the transcripts, proteins, mitochondria and other components necessary for early embryonic development. The intrinsic oocyte quality is one of the main factors affecting the embryo yield, the implantation rate and the rate of healthy offspring. It is obvious that a fertilized oocyte must reach the blastocyst stage within 6-9 days in the proper culture conditions to have a significant chance of inducing a pregnancy and producing an offspring. The ability to sustain the first week of embryonic development is clearly influenced by the follicular status from which the oocyte is obtained indicating that this developmental potential is inherent within certain oocytes. Since most early embryos that do not reach the blastocyst stage are blocked at or close to the maternal to zygotic transition (MZT)-stage, which occurs at the eight-cell stage in cattle, one could speculate that incompetent oocytes fail to appropriately activate the embryonic genome. Oocyte selection based on glucose-6-phosphate dehydrogenase (G6PDH) activity has been successfully used to differentiate between competent and incompetent bovine oocytes. Recently, molecular regulation of genes regulating biological process of Brilliant Cresyl Blue staining (BCB) selected oocytes and embryos was investigated to explain their variation in quality and developmental potentiality. This short review will highlights some of these efforts that have been done in this interesting area of research.

\section{More Information \\ *Address for Correspondence: Nasser Ghanem, Ph.D, Animal Production Department, Faculty of Agriculture, Cairo University Research Park, Cairo University, Egypt, Tel: +201002986157; +20223709081; +20235737966; +20235717355; Email: nassergo@agr.cu.edu.eg}

Submitted: March 18, 2021

Approved: April 07, 2021

Published: April 08, 2021

How to cite this article: Ghanem N, Samy R, Kassab EK, Khalil BSF, Kordy AA, et al.

Transcriptional profile of bovine preimplantation development selected based on G6PDH activity. J Stem Cell Ther Transplant. 2021; 5: 001-003.

DOI: 10.29328/journal.jsctt.1001023

Copyright: (c) 2021 Ghanem N, et al. This is an open access article distributed under the Creative Commons Attribution License, which permits unrestricted use, distribution, and reproduction in any medium, provided the original work is properly cited.

Keywords: G6PDH activity; Developmental competence; Gene expression; Oocyte; Embryo

Abbreviations: MZT: Maternal to Zygotic Transition; G6PDH: Glucose-6-Phosphate Dehydrogenase; BCB: Brilliant Cresyl Blue; $\mathrm{BCB}+$ :Brilliant Cresyl Blue Stained Oocytes; BCB-: Brilliant Cresyl Blue Non-Stained Oocytes; IVM: In Vitro Maturation; IVF: In Vitro Fertilization; ROS: Reactive Oxygen Species; NASP: Nuclear Autoantigenic Sperm Protein; TGFB1: Transforming Growth Factor 1; IFN Tau: Interferon Tau SSLP1: Secreted Seminal-Vesicle Ly-6 Protein 1; BAX: Bcl2-Associated X Protein; SCNT: Somatic Cell Nuclear Transfer

Check for updates

OPEn ACCEss

\section{Activity of glucose-6-phosphate based on Brilliant Cresyl Blue staining}

Immature oocytes are known to synthesize a variety of proteins, among them, glucose-6-phosphate dehydrogenase (G6PDH) [1]. G6PDH is synthesized and accumulates during the oocyte growth phase. The activity of this protein is decreased once this phase has been completed and oocytes are then likely to have achieved developmental competence [1]. Brilliant Cresyl Blue (BCB) is a dye that can be broken down by G6PDH [2] thus, oocytes that have finished their growth phase show a decreased G6PDH activity and exhibit a cytoplasm with a blue coloration $(\mathrm{BCB}+)$ while, growing oocytes are expected to have a high level of active G6PDH that resulted in colorless cytoplasm (BCB-). The BCB test has been successful in selecting pig oocytes for in vitro maturation (IVM) followed by in vitro fertilization (IVF) [2]. Cellular organelles like mitochondria [3] or protein activity such as glucose-6-phosphate dehydrogenase [4] have been shown to be good predictors of oocyte quality. In prepubertal goat oocytes, Rodríguez-González, et al. [5] showed that the BCB test permitted the selection of oocytes with larger diameters, higher percentages reaching Metaphase II, higher percentages of IVM-IVF oocytes with two pronuclei (normally fertilized) and higher embryo development up to the morula plus blastocyst stages compared to oocytes selected exclusively by morphological criteria. In mice, BCB staining was used efficiently for oocyte selection; however, the competence 
of the BCB+ oocytes may vary with oocyte diameter, animal sexual maturity and gonadotropin stimulation (Wu et al. 2007). Wongsrikeao, et al. [6] have shown that the selection of oocytes using the single BCB test improved the rates of nuclear maturation, monospermic fertilization of porcine oocytes, and subsequent embryonic development after IVF, as well as enhancement of embryo quality (increasing the total number of cells per blastocyst). Ahmed, et al. [7] indicated that there was no variation on preimplantation development of buffalo oocytes selected based on BCB staining. Moreover, bovine $\mathrm{BCB}+$ oocytes had a higher rate of blastocyst formation after somatic cell nuclear transfer (SCNT) than their BCBcounterpart's oocytes [8]. Recently, porcine BCB+ oocytes had a higher rate of cumulus expansion accompanied with increased Sonic hedgehog signaling ( $\mathrm{SHH}$ ) and reduced apoptosis incidence during in vitro maturation [9]. The data presented support the idea that BCB+ oocytes have a proper cytoplasmic and molecular microenvironment that support in vitro maturation and subsequent preimplantation embryo development of different mammalian species

\section{Gene regulating preimplantation development of ВСВ selected oocytes and embryos}

Torner, et al. (2008) have detected several genes reglating cell cycle expressed highly in BCB+ than BCB- oocytes. Among these genes, NASP that was first detected as a nuclear protein in testis of rabbit $[10,11]$ which increased the transcription profile in good quality bovine oocytes, that have increased preimplantation development [12]. Ghanem, et al. [13] have demonstrated that low developmentally competent BCBoocytes showed negative molecular response to increased oxygen tension by decreasing the transcript abundance of gene (CPT2) involved in mitochondrial metabolic activity. This could be due to action that low quality BCB- oocytes try to alleviate oxidative stress induced by reactive oxygen species (ROS) under high oxygen tension that was combined with reduced the profile of MAPK14 gene that orchestrate meiotic nuclear progression.

Indeed, bovine blastocyst embryos derived from $\mathrm{BCB}+$ selected oocytes contained more organelles like mitochondria compared with BCB- embryos [14]. However, the intercellular cytoplasmic lipid are similar in BCB- and BCB+ embryos. From molecular point of view, the transcriptional profile of genes regulating successful pregnancy establishment such as transforming growth factor 1 (TGFB1), Interferon tau (IFN tau), secreted seminal-vesicle Ly-6 protein 1 (SSLP1) gene expression was increased in $\mathrm{BCB}+$ blastocysts than BCB- counterparts. On the other hand, apoptotic index and expression profile of gene regulating apoptosis namely $\mathrm{Bcl} 2$ associated $\mathrm{X}$ protein (BAX) was increased its expression in $\mathrm{BCB}$ - compared with BCB+ embryos [14]. Additionally, relative transcript abundance of anti-apoptotic microRNA-21 and nuclear reprogramming related genes (SOX2 and CDX2) was increased in the $\mathrm{BCB}+$ compared to $\mathrm{BCB}$ - bovine blastocysts, while the profile Bax was decreased in BCB+ embryos [8].
These data provided above indicated that BCB+ oocytes potentially have a higher ability to develop to embryos after either in vitro fertilyation or nuclear somatic cell, and that BCB staining can be used to select developmentally competent oocytes for nuclear transfer.

\section{Conclusion}

Selection of oocytes based on the activity of G6PDH protein has showed some beneficial effect on embryo development and the quality of produced embryos. The variation on embryo development was referred to both changes on the molecular regulation of genes regulating developmental process of oocytes like cell cycle and mitochondrial activity and genes involved in nuclear reprogramming capacity and pregnancy establishment in BCB derived embryos.

\section{References}

1. Wassarman M. The mammalian ovum. In: Knobil E, Neil D, editors The physiology of reproduction, New York, USA: Raven Press. 1988; 1: 69-102.

2. Ericsson SA, Boice ML, Funahashi H, Day BN. Assessment of porcine oocytes using brilliant cresyl blue. Theriogenology1993; 39: 214.

3. El-Shourbagy SH, Spikings EC, Freitas M, St John JC. Mitochondria directly influence fertilisation outcome in the pig. Reproduction. 2006; 131: 233-245.

PubMed: https://pubmed.ncbi.nlm.nih.gov/16452717/

4. Alm H, Torner H, Loehrke B, Viergutz T, Ghoneim IM, et al. Bovine blastocyst development rate in vitro is influenced by selection of oocytes by brilliant cresyl blue staining before IVM as indicator for glucose-6-phosphate dehydrogenase activity. Theriogenology. 2005; 63: 2194-2205.

PubMed: https://pubmed.ncbi.nlm.nih.gov/15826683/

5. Rodriguez-Gonzalez E, Lopez-Bejar M, Izquierdo D, Paramio MT Developmental competence of prepubertal goat oocytes selected with brilliant cresyl blue and matured with cysteamine supplementation. Reprod Nutr Dev. 2003; 43: 179-187.

PubMed: https://pubmed.ncbi.nlm.nih.gov/12956317/

6. Wongsrikeao $\mathrm{P}$, Otoi $\mathrm{T}$, Yamasaki $\mathrm{H}$, Agung $\mathrm{B}$, Taniguchi $\mathrm{M}$, et al. Effects of single and double exposure to brilliant cresyl blue on the selection of porcine oocytes for in vitro production of embryos. Theriogenology. 2006; 66: 366-372.

7. Ahmed DAR, Ghanem N, Dessouki SM, Faheem MS, Gad AY, et al. Developmental Competence of Buffalo Oocytes Cultured Under Different Oxygen Tensions after Selection with Brilliant Cresyl Blue. World Vet J. 2020; 10: 246-253.

8. Sun J, Wang Y, Li R, Peng H, Hua S, et al. Oocytes Selected Using BCB Staining Enhance Nuclear Reprogramming and the In Vivo Development of SCNT Embryos in Cattle. PLoS One. 2012; 7: e36181. PubMed: https://pubmed.ncbi.nlm.nih.gov/22558373/

9. Lee S, Kang HG, Jeong PS, Nanjidsuren T, Song BS, et al. Effect of oocyte quality assessed by Brilliant Cresyl Blue (BCB) staining on cumulus cell expansion and Sonic Hedgehog Signaling in porcine during in vitro maturation. Int J Mol Sci. 2020; 21: 4423. PubMed: https://pubmed.ncbi.nlm.nih.gov/32580308/

10. Welch JE, O'Rand MG. Characterization of a sperm-specific nuclear autoantigenic protein. II. Expression and localization in the testis. Biol Reprod. 1990; 43: 569-578.

PubMed: https://pubmed.ncbi.nlm.nih.gov/2289011/

11. Welch JE, Zimmerman LJ, Joseph DR, O'Rand MG. Characterization of a sperm-specific nuclear autoantigenic protein. I. Complete sequence 
and homology with the Xenopus protein, N1/N2. Biol Reprod. 1990; 43: 559-568.

PubMed: https://pubmed.ncbi.nlm.nih.gov/2289010/

12. Dessie SW, Rings F, Hoelker M, Gilles M, Jennen D, et al. 2007.

13. Ghanem N, Ahmed DAR, Dessouki SM, Faheem MS, Gad AY, et al. Cellular and molecular alterations of buffalo oocytes cultured under two different levels of oxygen tension during in vitro maturation. Zygote.
2021; 1-11.

PubMed: https://pubmed.ncbi.nlm.nih.gov/33622439/

14. Fakruzzaman M, Bang JI, Lee KL, Kim SS, Ha AN, et al. Mitochondrial content and gene expression profiles in oocyte-derived embryos of cattle selected on the basis of brilliant cresyl blue staining. Animal Reproduction Science. 2013; 142: 19-27.

PubMed: https://pubmed.ncbi.nlm.nih.gov/24070583/ 